\title{
Schistosoma mansoni: estudo da patogenia da linhagem Santa Rosa (Campinas, SP, Brasil) em camundongos
}

\author{
Schistosoma mansoni: a study of pathogenesis of Santa Rosa \\ strain (Campinas, SP, Brasil) in mice \\ Leandro Yoshioka1, Eliana Maria Zanotti-Magalhães², \\ Luiz Augusto Magalhães ${ }^{2}$ e Arício Xavier Linhares ${ }^{2}$
}

\begin{abstract}
Resumo Realizou-se estudo comparativo da patogenia do S. mansoni da linhagem recentemente isolada no município de Campinas (SP, Brasil) denominada SR, com as linhagens BH (Belo Horizonte, MG, Brasil) e SJ (São José dos Campos, SP, Brasil). O estudo foi realizado em camundongos experimentalmente infectados com 70 cercárias oriundas de moluscos simpátricos às linhagens: B. glabrata para a linhagem $\mathrm{BH}$ e B. tenagophila para as linhagens SJ e SR. Os dados obtidos revelaram que esta nova linhagem do trematódeo, é menos patogênica que as demais tendo em vista o menor número de vermes, o menor número de ovos eliminados nas fezes, o menor número de granulomas e o menor diametro da reação granulomatosa em torno do ovo.
\end{abstract}

Palavras-chaves: Esquistossomose. Schistosoma mansoni. Linhagem. Patogenia.

Abstract The present paper reports the comparison between a newly isolated strain of S. mansoni in the city of Campinas (SP, Brazil) named SR, with the strains BH (Belo Horizonte, MG, Brazil) and SJ (São José dos Campos, SP, Brazil). The study was done using mice experimentally infected with 70 cercariae from sympatric snails: B. glabrata for the BH strain and B. tenagophila for the SJ and SR strains. The data obtained revealed that the new strain is less pathogenic than the other two, since it yielded fewer worms and shed eggs, a lower number of granulomas and a smaller granuloma size in the liver and intestine.

Key-words: Schistosomiasis. Schistosoma mansoni. Strain. Pathogenesis.

Numerosos casos autóctones da esquistossomose mansônica tem sido registrados no município de Campinas (SP, Brasil) e região, sendo o molusco transmissor Biomphalaria tenagophila. A taxa de infecção apresentada pelos caramujos colhidos no campo tem variado de $0,01 \%$ a $45 \%^{1911} 14$.

No Bairro Santa Rosa, em Campinas, onde casos autóctones da parasitose tem sido detectados, a taxa de infecção do molusco no campo foi de $8,7 \%$, em novembro de 1997, com eliminação de grande número de cercárias, o que permitiu a infecção de camundongos e o isolamento da linhagem SR (Santa Rosa).

O comportamento distinto das linhagens do Schistosoma mansoni, tanto no hospedeiro invertebrado como no hospedeiro definitivo ${ }^{13}{ }^{17}$, nos induziu a realizar um estudo comparativo da linhagem SR em relação às linhagens mineira $(\mathrm{BH})$ de Belo Horizonte (MG, Brasil) e paulista (SJ) de São José dos Campos (SP, Brasil), mantidas respectivamente em $B$. glabratae $B$. tenagophila das mesmas localidades.

Estudos realizados com as linhagens $\mathrm{BH}$ (Belo Horizonte) e SJ (São José dos Campos) do Schistosoma mansoniutilizando camundongos infectados com cercárias oriundas de moluscos simpátricos, mostraram que, um número bem menor de esquistossomos da linhagem $\mathrm{BH}$ provocou níveis equivalentes de nocividade aos provocados, por um maior número de vermes da linhagem $\mathrm{SJ}^{12}{ }^{13}$. Este fato poderia ser decorrente da maior suscetibilidade à infecção apresentada por B. glabratä202122 molusco hospedeiro intermediário da linhagem $\mathrm{BH}$. Em regiões endêmicas, onde $B$. glabrata é o hospedeiro intermediário, encontram-se com freqüência indivíduos com esquistossomose hepatosplênica descompensada, enquanto em áreas em que $B$. tenagophila é o vetor, a maioria dos portadores do parasita é assintomática ${ }^{4}$, sendo raros os casos de hepatosplenomegalia ${ }^{816}$.

\footnotetext{
1. Faculdade de Ciências Médicas da Universidade Estadual de Campinas, Campinas, SP. 2. Departamento de Parasitologia do Instituto de Biologia da Universidade Estadual de Campinas, Campinas, SP, Brasil.

Apoio financeiro: FAPESP, Processo No. 98/12657-2

Endereço para correspondência: Dra. Eliana Maria Zanotti Magalhães. Dept ${ }^{\circ}$ de Parasitologia/IB/UNICAMP. Caixa Postal 6109, Cidade Universitária, Barão Geraldo, 13083-970 Campinas, SP, Brasil.

Telefax: $55193788-6282$.

E-mail: emzm@obelix.unicamp.br

Recebido para publicação em 15/12/2000.
} 
Desde que o desenvolvimento da esquistossomose mansônica no hospedeiro vertebrado é dependente da compatibilidade do trematódeo ao molusco vetor ${ }^{2122}$, utilizamos na pesquisa moluscos simpátricos como hospedeiros das linhagens do trematódeo.

\section{MATERIAL E MÉTODOS}

Para o desenvolvimento do projeto foram constituídos 3 grupos de camundongos Swiss, SPF, com 30 dias de idade, expostos respectivamente as linhagens $\mathrm{BH}$, SJ e SR. Cada grupo foi constituído por 10 animais, submetidos, individualmente, à infecção por 70 cercárias. Os roedores de cada grupo foram infectados simultaneamente, através da exposição da cauda dos animais às larvas do trematódeo, por um período de duas horas.

As cercárias da linhagem $\mathrm{BH}$ foram provenientes de B. glabrata, nascidas em laboratório e originadas de populações obtidas em Belo Horizonte. As cercárias da linhagem SJ foram obtidas de $B$. tenagophila nascidas em laboratório e originadas de populações da região do Vale do Rio Paraíba (São José dos Campos). As cercárias da linhagem SR foram oriundas de $B$.tenagophila nascidas em laboratório e originadas de populações do Jardim Santa Rosa, em Campinas. Ao final do período de exposição dos camundongos às cercárias, foi determinado o número de cercárias penetrantes ${ }^{10}$.

A verificação do número de ovos de $S$. mansoni eliminados nas fezes foi feita através do método de Kato$\mathrm{Katz}^{6}$. A pesquisa de ovos nas fezes foi realizada a partir da $3^{\text {a }}$ semana de exposição dos camundongos às cercárias, sendo que no dia em que se completou cada semana houve a preparação de três lâminas. $O$ resultado apresentado foi, uma média aritmética da quantidade de ovos encontrados nas lâminas analisadas. A pesquisa dos ovos foi realizada, utilizandose um pool de fezes dos animais infectados.

Por ocasião do sacrifício, ao final da $8^{a}$ semana, os vermes foram coletados por perfusão do sistema porta- hepático ${ }^{19}$. Foram anotados os números de vermes machos e fêmeos encontrados isolados e de casais.

Por ocasião do sacrifício, fragmentos do fígado, baço, intestino (cólon ascendente), pulmão e pâncreas foram fixados em Bouin aquoso, com a finalidade de realização de cortes histológicos de $5 \mu \mathrm{m}$ de espessura para contagem e medição dos granulomas esquistossomóticos. Os cortes histológicos foram corados com Tricrômico de Masson.

A determinação do número e tamanho dos granulomas esquistossomóticos no fígado, baço, intestino, pulmão e pâncreas foi feita através da utilização de microscopia óptica, obtendo-se o número de reações granulomatosas verificadas em 6 campos ópticos, aleatoriamente examinados.

Foram medidas as reações granulomatosas que continham ovos de $S$. mansoni, tomando-se os diâmetros maior e menor através da utilização da ocular micrométrica ${ }^{21}$.

Os dados obtidos foram submetidos a análise estatística comparando as três linhagens estudadas através da análise da variância, considerando o número de cercárias penetrantes, o número de vermes (machos e fêmeas isolados, casais e vermes totais), o número de granulomas no fígado, intestino, pulmões, pâncreas e baço e, o tamanho das reações granulomatosas no fígado e no intestino. O número de ovos de $S$. mansoni eliminados nas fezes, o número de casais de $S$. mansoni e a relação entre o número de granulomas no fígado e no intestino com o número de casais foram analisados pelo teste de qui-quadrado.

\section{RESULTADOS}

As taxas de infecção apresentadas pelos moluscos expostos a 10 miracídios e que forneceram as cercárias para a infecção dos camundongos foram as seguintes: B. glabrata infectada com a linhagem $\mathrm{BH}: 21 \%$; B. tenagophila infectada com a linhagem SJ: $11,7 \%$ e B. tenagophila infectada com a linhagem SR: 16,7\%. A análise estatística referente à infecção de $B$. glabrata infectada com a linhagem $\mathrm{BH}$ e $B$. tenagophila infectadas com as linhagens SJ e SR, revelou que as taxas de infecção dos moluscos não diferiram significativamente entre si $\left(x^{2}=5,99\right)$ considerando o nível de $5 \%$ de significância.

Os dados referentes a capacidade de penetração das cercárias da linhagem BH, SJ e SR de S. mansoni estão apresentados na Tabela 1. Comparando-se o número de cercárias penetrantes das três linhagens estudadas (BH, SJ e SR) verificou-se que não houve diferença significativa $(p<0,4473)$.
O número de ovos encontrados nas fezes dos camundongos infectados com as linhagens $\mathrm{BH}$, SJ e SR de S. mansoni está referido na Tabela 2. A detecção de ovos de $S$. mansoni nas fezes foi observada a partir da $5^{\text {a }}$ semana de infecção em camundongos infectados com as linhagens $\mathrm{BH}$ e SJ. Camundongos infectados com a linhagem SR apresentaram eliminação de ovos a partir da 6a semana de infecção. O estudo estatístico do número de ovos de $S$. mansoni nas fezes (teste do qui-quadrado) mostrou haver diferença significativa entre as linhagens nos períodos analisados ( $p=0,001)$. Considerando a $7^{a}$ e a $8^{a}$ semanas de infecção, observou-se maior número de ovos nas fezes de animais infectados com a linhagem SJ, seguindo-se em valores decrescentes, animais infectados com a linhagem BH e SR $(p=0,001)$. Na $8^{a}$ semana de infecção, os camundongos eliminaram número significativamente maior de ovos do trematódeo pelas fezes $(p<0,0072)$ do que nas semanas anteriores. 
Tabela 1- Número médio de cercárias penetrantes, de vermes machos e femeos, acasalados e totais em camundongos infectados com as linhagens $B H$, SJ e SR de S. mansoni.

\begin{tabular}{lrrr}
\hline & \multicolumn{3}{c}{ Linhagens } \\
\cline { 2 - 4 } Parâmetros & \multicolumn{1}{c}{ BH } & \multicolumn{1}{c}{ SR } \\
\hline Número de cercárias penetrantes & 68,4 & 67,4 & 67,6 \\
Número de vermes machos & 10,4 & 4,0 & 1,7 \\
Número de vermes femeos & 5,4 & 4,7 & 3,1 \\
Número de vermes acasalados & 11,0 & 15,2 & 4,7 \\
Número de vermes totais & 37,8 & 39,1 & 14,2 \\
\hline
\end{tabular}

O número de vermes encontrados no sistema portamesentérico dos camundongos infectados com as linhagens $\mathrm{BH}$, SJ e SR de S. mansoni na 8ª semana de infecção está apresentado na Tabela 1. Os vermes acasalados foram encontrados principalmente nas veias mesentéricas. Comparando-se o número de cercárias que penetraram e o número de vermes recuperados, observa-se que somente $21 \%$ das cercárias SR desenvolveram-se em vermes adultos, enquanto $55 \%$ e $58 \%$ das cercárias, respectivamente das linhagens $\mathrm{BH}$ e SJ desenvolveram-se em vermes adultos. Através da análise estatística observou-se que as linhagens $\mathrm{BH}$ e SJ apresentaram número significativamente maior de vermes fêmeos $(p<0,0017)$ do que a linhagem SR. Fato semelhante foi verificado para o número de vermes machos $(p<0,0003)$, para o número de vermes acasalados $(p<0,0046)$ e para o número de vermes totais $(p<0,0006)$. O número de casais de $S$. mansoni recuperados diferiu significativamente entre as três linhagens estudadas $(p<0,0001)$. Comparando as linhagens entre si em relação a esse parâmetro, a linhagem SJ apresentou maior número de casais do que as linhagens $\mathrm{BH}(\mathrm{p}=0,0098)$ e $\mathrm{SR}(\mathrm{p}<0,0001)$. Comparando as linhagens $\mathrm{BH}$ e $\mathrm{SR}$ número significativamente maior de casais foi recuperado em animais infectados com a linhagem $\mathrm{BH}(p<0,0001)$.

O número de reações granulomatosas encontradas nas vísceras dos camundongos infectados com as linhagens $\mathrm{BH}$, SJ e SR de S. mansoni está apresentado na Tabela 3. O número de reações granulomatosas no

Tabela 3 - Número médio de granulomas esquistossomóticos por área $\left(2,5717 \mathrm{~mm}^{2}\right)$ de tecido observado em animais infectados com as linhagens BH, SJ e SR de S. mansoni.

\begin{tabular}{llcl}
\hline & \multicolumn{3}{c}{ Linhagens } \\
\cline { 2 - 4 } Órgãos & $\mathrm{BH}$ & $\mathrm{SJ}$ & $\mathrm{SR}$ \\
\hline Baço & 0,66 & 0,25 & 0,35 \\
Fígado & 6,05 & 3,33 & 1,78 \\
Intestino & 1,55 & 0,96 & 0,65 \\
Pâncreas & 0,68 & 0,32 & 0,17 \\
Pulmão & 0,68 & 0,41 & 0,12 \\
\hline
\end{tabular}

baço foi significativamente diferente nas linhagens $\mathrm{BH}$, SJ e SR $(p<0,0483)$. Camundongos infectados com a linhagem $\mathrm{BH}$ de $S$. mansoni apresentaram número significativamente maior de granulomas no baço do que animais infectados com a linhagem SJ. Na linhagem SR, o número de granulomas esplênicos foi menor do
Tabela 2 - Número de ovos de S. mansoni das linhagens BH, SJ e SR por grama de fezes.

\begin{tabular}{lrrr}
\hline Tempo de infecção & \multicolumn{3}{c}{ Linhagens } \\
\cline { 2 - 4 } (semanas) & $\mathrm{BH}$ & $\mathrm{SJ}$ & $\mathrm{SR}$ \\
\hline $3^{\mathrm{a}}$ & 0 & 0 & 0 \\
$4^{\mathrm{a}}$ & 0 & 0 & 0 \\
$5^{\mathrm{a}}$ & 8 & 8 & 0 \\
$6^{\mathrm{a}}$ & 8 & 0 & 16 \\
$7^{\mathrm{a}}$ & 488 & 1.112 & 280 \\
$8^{\mathrm{a}}$ & 1.368 & 1.800 & 624 \\
\hline
\end{tabular}

que na linhagem $\mathrm{BH}$, porém a diferença não foi significativa. Comparando-se as linhagens SJ e SR em relação ao número de granulomas no baço, observouse que a linhagem SJ apresentou um número menor de reações granulomatosas, porém a diferença não foi significativa. O número de reações granulomatosas no fígado diferiu significativamente entre as linhagens estudadas $(p<0,0001)$. Animais infectados com a linhagem $\mathrm{BH}$ de $S$. mansoni apresentaram número significativamente maior de granulomas hepáticos do que animais infectados com as linhagens SJ e SR. Entre as linhagens paulistas (SJ e SR), a linhagem SJ apresentou número significativamente maior de reações granulomatosas no fígado do que a linhagem SR. Com relação ao número de granulomas no intestino, verificouse diferença significativa entre as linhagens $(p<0,0320)$, sendo que a linhagem $\mathrm{BH}$ induziu maior número de reações que a linhagem SR. Entretanto, o número de granulomas intestinais em animais infectados com as linhagens SJ e SR não diferiu significativamente entre si. O mesmo resultado foi verificado para o pâncreas $(p<0,0260)$ e para o pulmão $(p<0,0035)$. A linhagem $B H$ apresentou maior número de granulomas do que a linhagem SR, contudo, não diferiu significativamente da linhagem SJ. Esta última linhagem apresentou um número de granulomas não significativamente diferente do número de granulomas observados nas linhagens $\mathrm{BH}$ e SR. Considerando os órgãos examinados e as linhagens estudadas, o fígado foi a víscera que apresentou maior número de granulomas esquistossomóticos em todas as linhagens. Nas linhagens $\mathrm{BH}$ e SJ, o intestino foi a segunda víscera em número de reações granulomatosas, seguido pelo pulmão, pâncreas e baço, nos quais o número de lesões não diferiu significativamente. Para a linhagem SR, o número de granulomas no intestino, no baço, no pâncreas e no pulmão não diferiu significativamente. Correlacionando o número de granulomas no fígado com o número de casais de $S$. mansoni, foi verificado que houve diferença significativa entre as linhagens $(p<0,0001)$, sendo que na linhagem BH esta relação foi significativamente maior do que na linhagem SJ $(p=0,0057)$ e na linhagem SR $(p<0,0001)$. Entre as linhagens SJ e SR, esta última linhagem apresentou relação significativamente maior de número de granulomas no fígado por número de casais $(p=0,0329)$. Não foram observadas diferenças significativas entre 
as linhagens, quando se correlacionou o número de granulomas no intestino com o número de casais de $S$. mansoni $(\mathrm{p}=0,1411)$.

O tamanho das reações granulomatosas encontradas nas vísceras dos camundongos infectados com as linhagens $\mathrm{BH}$, SJ e SR de S. mansoni está apresentado na Tabela 4. Os valores foram obtidos através do diâmetro médio dos granulomas esquistossomóticos. A análise estatística referente ao tamanho de granulomas, considerou apenas àqueles verificados no fígado e intestino. No fígado, o tamanho da reação granulomatosa diferiu significativamente $(p<0,0001)$ entre as linhagens, sendo observados que em animais infectados com a linhagem $\mathrm{BH}$ as lesões em torno do ovo foram significativamente maiores do que aquelas observadas nas linhagens SJ e SR. Nestas duas últimas linhagens, entretanto, o tamanho dos granulomas esquistossomóticos presentes no fígado, foi semelhante. Em relação ao intestino, o diâmetro médio dos granulomas não diferiu significativamente $(p<0,7071)$ entre as linhagens estudadas.

Tabela 4 - Diâmetro médio dos granulomas esquistossomóticos ( $\mathrm{mm}$ ) observados em órgãos de animais infectados com as linhagens $B H, S J$ e SR de S. mansoni.

\begin{tabular}{lccr}
\hline & \multicolumn{3}{c}{ Linhagens } \\
\cline { 2 - 4 } Órgãos & $\mathrm{BH}$ & $\mathrm{SJ}$ & $\mathrm{SR}$ \\
\hline Baço & 0,14 & - & - \\
Fígado & 0,21 & 0,18 & 0,16 \\
Intestino & 0,22 & 0,21 & 017 \\
Pâncreas & 0,24 & 0,33 & - \\
Pulmão & 0,16 & 0,23 & 0,24 \\
\hline
\end{tabular}

\section{DISCUSSÃO}

Diferenças de comportamento entre linhagens de S. mansoni no hospedeiro vertebrado são esperadas, como manifestação da expressão genotípica do trematódeo. Dessa forma verificou-se que a linhagem egípcia era menos virulenta, apesar do grande número de vermes observados ${ }^{17}$. Em relação às linhagens $\mathrm{BH}$ e SJ, verificou-se que embora o número de vermes que se desenvolveram nos camundongos tenha sido semelhante nas duas linhagens, a linhagem $\mathrm{BH}$ foi mais patogênica, determinando maior mortalidade dos animais em conseqüência do maior número de reações granulomatosas ${ }^{13}$. Na linhagem SR, menor número de vermes adultos se desenvolveram, quando comparada com as linhagens $\mathrm{BH}$ e SJ, embora o número de cercárias penetrantes tenha sido semelhante. Nos camundongos infectados com as linhagens $\mathrm{BH}$ e SJ observaram-se números semelhantes de vermes adultos. De modo geral, nas infecções causadas por helmintos, a patogenicidade está diretamente relacionada com a carga parasitária. Em se tratando do S. mansoni, a carga parasitária é de importância relativa, desde que a patogênese das infecções por este trematódeo está também relacionada com a presença de reações granulomatosas em torno dos ovos do parasita e portanto, com a capacidade de oviposição dos vermes. Estudos realizados com animais infectados com diversas linhagens de S. mansoni mostraram diversidades na quantidade, densidade e distribuição dos ovos do trematódeo nos tecidos $^{2517}$. Estudo realizado com as linhagens de S. mansoni de Porto Rico, do Brasil, do Egito e da Tanzania, originadas de moluscos simpátricos, mostrou que a linhagem da Tanzania foi menos patogênica, apresentando menor produção de ovos pelos vermes e um retardamento no processo de necrose observada na reação granulomatosa ${ }^{18}$.
Embora as diferenças nem sempre tenham sido significativas, verificamos em nossos resultados que nos camundongos infectados com a linhagem $\mathrm{BH}$ o número de reações granulomatosas em todos os órgãos estudados foi maior, quando comparado com o número de granulomas verificados nas linhagens SJ e SR. Estes dados confirmam, a maior patogenicidade da linhagem $\mathrm{BH}$ verificada anteriormente ${ }^{7}{ }^{13}$. Considerando as reações granulomatosas no fígado apresentadas pela linhagem SJ, estas foram significativamente mais numerosas que as observadas na linhagem SR. O menor número de vermes adultos recuperados nesta última linhagem, produziu menor número de ovos do trematódeo e como conseqüência menor distribuição no tecidos e menor eliminação de ovos pelas fezes. $O$ tamanho das reações granulomatosas mostrou também que as lesões foram maiores nas infecções pela linhagem $\mathrm{BH}$, enquanto nas linhagens paulistas (SJ e $\mathrm{SR}$ ), os diâmetros das reações foram semelhantes entre si. O menor diâmetro dos granulomas e o menor número de reações granulomatosas observados nas infecções pela linhagem SR, poderiam ser decorrentes do início tardio da oviposição (6a semana de infecção) verificado nos animais infectados por esta linhagem do trematódeo. O maior número de granulomas hepáticos associados ao maior diâmetro dos granulomas observados na linhagem $\mathrm{BH}$ poderiam explicar a maior patogenicidade desta linhagem, quando comparada às linhagens $S J$ e $S R$, aqui utilizadas. A reação granulomatosa em torno do ovo do S. mansoni, controlada em sua formação e regulação por mecanismos imunocelulares, tem sido estudada profundamente não se conhecendo a totalidade dos antígenos e dos mecanismos envolvidos na indução, formação e regulação da reação granulomatosa ${ }^{15}$. 


\section{REFERÊNCIAS BIBLIOGRÁFICAS}

1. Acceturi ELP, Deberaldini ER, Gotto MMF, Magalhães LA, Pedro RJ. Tentativa de erradicação de foco de esquistossomose mansônica em região de baixa endemicidade. In: Resumos do V Congresso Brasileiro de Parasitologia, Rio de Janeiro p.78, 1980.

2. Anderson LA, Cheever AW. Comparison of geographical strains of Schistosoma mansoni in mouse. Bulletin of World Health Organization 46:233-242, 1972.

3. Conceição MJ, Coura JR. Comportamento experimental em Biomphalaria glabrata de amostras de $S$. mansoni isoladas de pacientes com diferentes formas clínicas de esquistossomose. In: Resumos do XIX Congresso da Sociedade Brasileira de Medicina Tropical, Rio de Janeiro p.88, 1983.

4. Dias LCS, Glasser CM, Etzel A, Kawazoe U, Hoshino-Shimizu S, Kanamura HY, Cordeiro JA, Marçal Jr O, Carvalho JF, Gonçalves Jr F, Patucci R. The epidemiology and control of schistosomiasis mansoni where Biomphalaria tenagophila is the snail host. Revista de Saúde Pública São Paulo 22:462-463, 1988.

5. Kassim OO, Cheever AW, Richards CS. Schistosoma mansoni: mice infected with different worm strains. Experimental Parasitology 48:220-224, 1979.

6. Katz N, Chaves A, Pellegrino J. A simple device for quantitative stool thick-smear technique in Schistosomiasis. Revista do Instituto de Medicina Tropical de São Paulo 14:397-400, 1972.

7. Lemos Neto RC, Magalhães LA, Piedrabuena AE. Alguns aspectos referentes ao estudo de linhagens de Schistosoma mansoni Sambon, 1907, provenientes dos estados de Minas Gerais e de São Paulo, Brasil. Revista de Saúde Pública São Paulo 12:277-290, 1978.

8. Lima JN. Estudo clínico e terapêutico da esquistossomose mansônica em menores de 15 anos do Vale do Ribeira, SP: comparação do oxamniquine, praziquantel e associação dessas drogas $m$ baixas doses. Tese de Mestrado, Universidade Estadual de Campinas, Campinas, SP, 1991.

9. Magalhães LA. Aspectos da epidemiologia da esquistossomose mansoni na cidade de Campinas, SP. Revista Paulista de Medicina 72:267-268, 1968.

10. Magalhães LA. Técnica para avaliação da viabilidade de penetração de cercárias Schistosoma mansoni em Mus musculus. Hospital 75:1663-1666.

11. Magalhães LA, Camargo LAP, Muniz JRO, Andrade D. Novo foco de esquistossomose mansoni em Campinas, SP, Brasil. Revista Paulista de Medicina 70:207-208, 1967.

12. Magalhães LA, Carvalho JF. Verificação do número de machos e fêmeas de Schistosoma mansoni capturados em camundongos infectados com duas cepas do helminto. Revista da Sociedade Brasileira de Medicina Tropical 3:253-254, 1969.

13. Magalhães LA, Carvalho JF. Sobre o comportamento de duas linhagens de Schistosoma mansoni Sambon, 1907. Proposição para método de estudo quantitativo. Revista da Sociedade Brasileira de Medicina Tropical 10:169-194, 1976.

14. Magalhães LA, Dias LCS, Piza JT, Takaku L, Pereira AA. Aspectos epidemiológicos da esquistossomose mansônica na região da represa de Americana, Estado de São Paulo. Revista de Saúde Pública 7:21-28, 1973.

15. Newport GR, Colley DG. Schistosomiasis. In: Warren KS (ed) Immunology and molecular biology of parasitic infections, $3^{\text {rd }}$ edition, Blackwell, Oxford, p.387-437, 1993.

16. Santos NR. Esquistossomose mansônica autóctone no Vale do Médio Paraíba, Estado de São Paulo, Brasil: contribuição para o estudo da zona endêmica. Tese de Doutorado, Universidade de São Paulo, São Paulo, SP, 1967.

17. Saoud MFA. The infectivity and pathogenicity of geographical strains of Schistosoma mansoni. Transactions of the Royal Society of Tropical Medicine and Hygiene 60:585-600, 1966.

18. Warren KS. A comparison of Puerto Rican, Brazilian, Egyptian and Tanzanian strains of Schistosoma mansoni in mice: penetration of cercariae, maturation of schistosomes and production of liver disease. Transactions of the Royal Society of Tropical Medicine and Hygiene 61:795-802, 1967.

19. Yolles TK, Moore DU, De Ginsti DL, Ripson CA, Meleney HE. A technique for the perfusion of laboratory animals for the recovery of schistosomes. Journal of Parasitology 33:419-26, 1947.

20. Zanotti-Magalhães EM, Magalhães LA, Carvalho JF. Relação entre a patogenicidade do Schistosoma mansoni em camundongos e a suscetibilidade do molusco vetor. I- Infecciosidade das cercárias e carga de vermes. Revista de Saúde Pública São Paulo 25:359-366, 1991.

21. Zanotti-Magalhães EM, Magalhães LA, Carvalho JF. Relação entre a patogenicidade do Schistosoma mansoni em camundongos e a suscetibilidade do molusco vetor. II- Número de ovos nas fezes e número e tamanho dos granulomas nas vísceras. Revista de Saúde Pública São Paulo 27: 412-420, 1993.

22. Zanotti-Magalhães EM, Magalhães LA, Carvalho JF. Relação entre a patogenicidade do Schistosoma mansoni em camundongos e a suscetibilidade do molusco vetor. IIIMortalidade, pesos corporal e das vísceras. Revista de Saúde Pública São Paulo 29:265-270, 1995 